\section{Rauchverbote schützen Kinderlungen}

\author{
Darf in der Öffentlichkeit weniger geraucht werden, müssen Kinder \\ auch zu Hause weniger Passivrauch ertragen. Das macht sich offen- \\ bar klinisch bemerkbar - etwa indem die Zahl der Krankenhaus- \\ einweisungen wegen Asthma sinkt.
}

W ährend in Deutschland noch über einen geeigneten Nichtraucherschutz debattiert wird und jedes Bundesland seine eigenen Lösungen favorisiert, wird die Studienlage zum gesundheitlichen Nutzen solcher Verbote immer eindrucksvoller. Längst bekannt ist, dass durch strenge Schutzvorschriften die Herzinfarktrate sinkt. Nach Daten einer Metaanalyse geht die Zahl der Klinikeinweisungen wegen Herzinfarkt im ersten Jahr nach einem öffentlichen Rauchverbot um $17 \%$, nach drei Jahren sogar um $36 \%$ zurück. Das lässt sich nicht mehr allein damit erklären, dass die Passivrauchbelastung sinkt, sondern damit, dass überhaupt weniger geraucht wird. Und davon scheinen auch Kinder zu profitieren: Ging man bislang eher davon aus, dass Kinder durch öffentliche Rauchverbote noch mehr Passivrauch zu atmen bekommen, weil ihre Eltern dann mehr zu Hause rauchen, so scheint nach neuen Studien genau das Gegenteil der Fall zu sein: Die Passivrauchbelastung sinkt sowohl in der Öffentlichkeit als auch zu Hause.

So hatten US-amerikanische Forscher um Dr. Melanie Dove aus Boston die Belastung in Countys mit strikten

Rauchverboten - etwa in Restaurants, in Einkaufszentren, an öffentlichen Plätzen lastung in Countys ohne eine solche Einschränkungen verglichen. Dazu hattn sie Blutproben von knapp 11.500 Kindern und Jugendlichen analysiert [1]. Im Blickpunkt standen die Serum-Konzentrationen von Cotinin, einem langlebigen Nikotin-Abbauprodukt. Gemessen wurde Cotinin in vier Untersuchungsphasen zwischen 1999 und 2006.

Bei Kindern und Jugendlichen aus Nichtraucher-Haushalten ergab sich folgendes Bild: Obwohl in diesen Haushalten niemand rauchte, ließ sich Cotinin bei $54 \%$ der Minderjährigen nachweisen, die in Countys ohne Rauchverbote lebten. Dagegen fand sich Cotinin nur bei $25 \%$ der Minderjährigen aus Gegenden mit strikten Rauchverboten. Als nachweisbar galten dabei CotininWerte von über $0,05 \mathrm{ng} / \mathrm{ml}$. Bemerkbar machte sich zudem, dass im Untersuchungszeitraum immer mehr USStaaten und -Countys strikte Nichtraucher-Schutzvorschriften einführten. So sank insgesamt der Anteil der Kinder und Jugendlichen mit Cotinin im Blut von $64 \%$ im Jahr 2000 auf $49 \%$ im oder gar in privaten Autos - mit der Be-
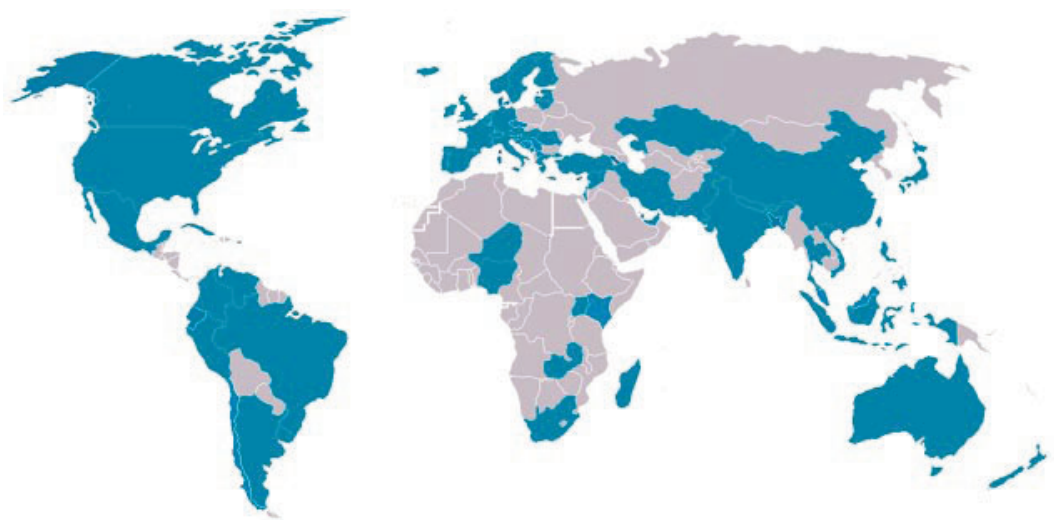

Gesetzliche Rauchverbote sind weltweit gesehen inzwischen nicht mehr die Ausnahme, sondern die Regel: Zuletzt hat China am 1. Mai 2011 nachgezogen.
Jahr 2006 - bezogen jeweils auf Nichtraucher-Haushalte. In Raucherhaushalten hatten praktisch alle Kinder nachweisbare Cotinin-Spiegel, unabhängig von den lokalen Schutzvorschriften. Doch auch hier nutzen die Schutzvorschriften: Je restriktiver die Verbote in einzelnen Regionen waren, umso geringer war der Anteil der Raucher und damit der Anteil von Kindern, die zu Hause passiv rauchten.

Hinweise auf einen direkten klinischen Nutzen von Rauchverboten sahen jetzt auch Forscher um Dr. Daniel Mackay aus Glasgow. Sie hatten die Rate von Klinikeinweisungen bei Kindern unter 15 Jahren aufgrund von Asthmaexazerbationen in den Jahren 2000 bis 2009 untersucht. Im März 2006 war in Schottland ein striktes Rauchverbot inkraft getreten. Bis zur Einführung des Verbots wurden pro Monat etwa 200 Kinder wegen Asthmaanfällen klinisch behandelt, nach der Einführung war die Zahl bis Ende 2009 auf etwa 120 pro Monat gesunken [3]. Ähnliches war zuvor im USBundesstaat Arizona nach Einführung eines allgemeinen öffentlichen Rauchverbots beobachtet worden. Hier war insgesamt die Zahl der asthmabedingten Klinikeinweisungen gesunken [2]. Als Grund für den klinischen Effekt nennt auch das Team um Mackay den reduzierten Raucheranteil in der Bevölkerung.

Fazit: Gesetze zum Nichtaucherschutz reduzieren nicht nur unmittelbar die öffentliche Belastung durch Passivrauchen, sondern verringern mittelfristig auch die Zahl der Raucher in der Bevölkerung - was nicht zuletzt auch den Kinderlungen zugute kommt. red

1. Dove MS et al. Dove MS et al. Smokefree air laws and secondhand smoke exposure among nonsmoking youth. Pediatrics 2010; 126: 80-7

2. Herman PM et al. Hospital admissions for acute myocardial infarction, angina, stroke, and asthma after implementation of Arizona's comprehensive statewide smoking ban. Am J Public Health 2011; 101: 491-6

3. Mackay D et al. Smoke-free legislation and hospitalizations for childhood asthma. N Engl J Med 2010; 363: 1139-45 